\title{
THE ROLE OF AIRWAY MANAGEMENT ON FEEDING DIFFICULTIES IN CHILDREN WITH PFEIFFER SYNDROME
}

\author{
SUNIL SHARMA ${ }^{1}$, WENDY BLUMENOW ${ }^{2}$, HANNAH EMERSON ${ }^{1}$ SUJATA DE $^{1}$
}

1DEPARTMENT OF PAEDIATRIC ENT SURGERY, ALDER HEY CHILDREN'S NHS FOUNDATION TRUST, LIVERPOOL, UNITED KINGDOM.

2DEPARTMENT OF PAEDIATRIC SPEECH AND LANGUAGE THERAPY, ALDER HEY CHILDREN'S NHS FOUNDATION TRUST, LIVERPOOL, UNITED KINGDOM.

\section{Conclusions: This study suggests that nasopharyngeal airway insertion (compared to tracheostomy) may be associated with improved outcomes regarding feeding in children with Pfeiffer syndrome.}
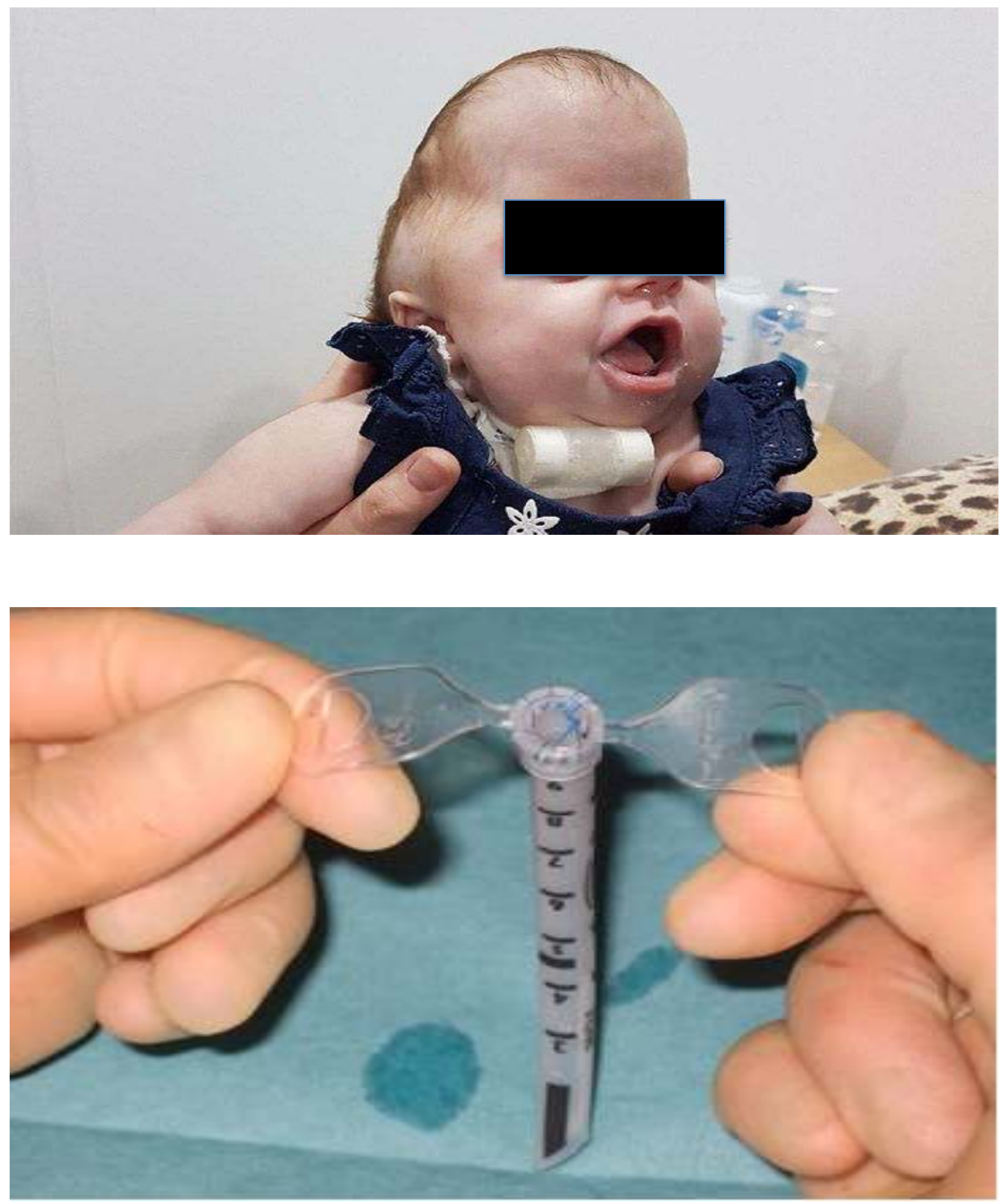

\section{E}

